Full Paper: $N$-Methylol reagents are conventional crosslinking agents that are still widely used in textile industry to produce crease-resistant cotton fabrics. In this work serine proteases were used to recover the strength of fabrics, crosslinked with $N$-hydroxymethylacrylamide. Nearly one half of the strength loss of crosslinked cotton fabrics could be restored after protease treatment, while the wrinkle recovery angle (WRA) decreased only slightly. The enzymatic hydrolysis of the amide cross-links in the durable pressed cellulose was confirmed by FT-IR analysis and dyeability with an acid dye.

Effect of protease concentration on the tensile strength recovery, WRA and acid dye dyeability at $30 \mathrm{~min}$ reaction time.

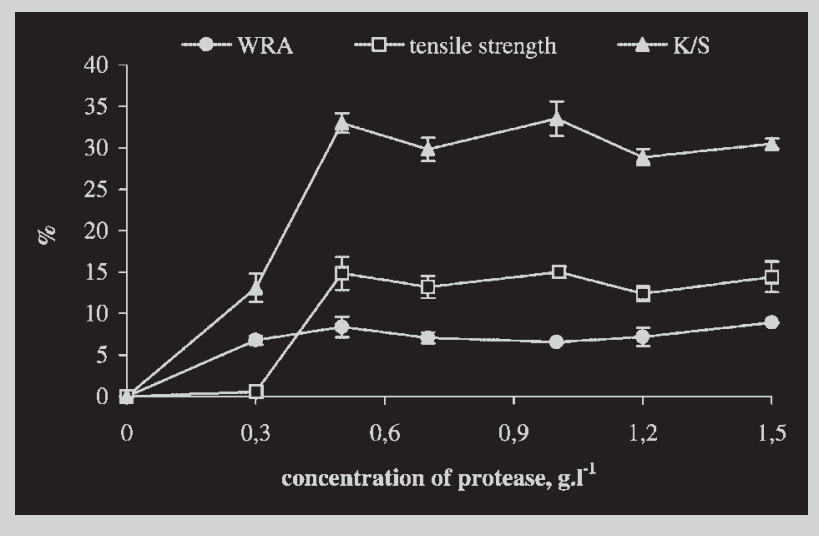

\title{
Proteases to Improve the Mechanical Characteristics of Durable Press Finished Cotton Fabrics
}

\author{
Maria Stamenova, ${ }^{1}$ Tzanko Tzanov, ${ }^{2}$ Rossitza Betcheva, ${ }^{1}$ Artur Cavaco-Paulo ${ }^{* 2}$ \\ ${ }^{1}$ University of Chemical Technology and Metallurgy, 1756 Sofia, Bulgaria \\ ${ }^{2}$ Departamento de Engenharia Têxtil, Universidade do Minho, Campus de Azurém, 4800-058 Guimarães, Portugal \\ Fax: +351 253 510293; E-mail: artur@det.uminho.pt
}

Keywords: crosslinking; enzymes; proteases; strength recovery

\section{Introduction}

Durable press finishing processes are widely used in the textile industry to impart wrinkle-resistance to cotton fabrics and garments. Methylolamide adducts of formaldehyde and amides are common crosslinking agents for finishing of cellulosic fibers materials. Nowadays only a few formaldehyde-free finishing agents are commercialized and are still quite expensive to replace entirely the traditional resins. The adducts of amides have large share in the pallet of conventional durable-press products for textile application. ${ }^{[1]}$ One product of low formaldehyde content that became of commercial importance is the $N$-hydroxymethylacrylamide. It reacts by $N$-methylol group with cellulose in a single step, using an acid-acting catalyst: zinc nitrate $^{[2,3]}$ The crease-resistance effect is provided by the formation of a network of ether bonds between each molecule of the reagent and cellulose (Scheme 1).

It is a well-known drawback of any crease-resistance treatment on cotton fabrics that the improvement of the dimensional stability and wrinkle resistance is always correlated with significant decrease of the tensile strength. ${ }^{[4,5]}$ The loss of fabric mechanical strength has been attributed to two main factors: acid-catalyzed depolymerisation and crosslinking of cellulose molecules. ${ }^{[4,6]}$ The fabric strength loss caused by crosslinking is described as a reversible process and could be restored by removing chemically the crosslinks. ${ }^{[7]}$ However, the partial removal of the crosslinks, so that the desired crease-resistance is preserved, requires the use of reagents that have minimal or controlled penetration beyond the fiber surface. Normally the classical alkaline or acid hydrolysis (depending on the bonds to be broken) is difficult to be controlled and might damage seriously the durable press effect and even the fabrics. In our previous work lipases were used to restore partially the strength loss of cotton fabric crosslinked with 1,2,3,4butanetetracarboxylic acids. It was shown that the enzymatic hydrolysis of the ester linkages resulted in $10 \%$ strength recovery, coupled with slight deterioration of the crease resistance effect. ${ }^{[8]}$ Considering the hydrolysis options existing in the structure shown in Scheme 1 it could be concluded that currently there is no commercially available enzymatic system, which specifically could attack the ether links between $N$-hydroxymethyl acrylamide and cellulose. However, several proteases have the potential to destroy the amide bonds in $N$-hydroxymethylacrylamide. The proteolytic enzymes (proteases) catalyze the hydrolysis of certain peptide bonds in protein molecules. 


\section{$\mathrm{R}_{\mathrm{Cell}}-\mathrm{OH}+\mathrm{HO}-\mathrm{CH}_{2}-\mathrm{NH}-\mathrm{CO}-\mathrm{CH}=\mathrm{CH}_{2} \rightarrow \mathrm{R}_{\mathrm{Cell}}-\mathrm{O}-\mathrm{CH}_{2}-\mathrm{NH}-\mathrm{CO}-\mathrm{CH}_{2}-\mathrm{CH}_{2}-\mathrm{O}-\mathrm{R}_{\text {Cell }}$}

Scheme 1. Reaction between $N$-hydroxymethylacrylamide and cellulose.

Different proteases act selectively on the peptide bonds, which depends on the nature of the adjacent amino acid side chains and the spatial arrangement of the polypeptide chain in the protein structure. ${ }^{[9]}$ Serine-type proteases could act on the amide bonds in the cross-linked cellulose structure. The serine proteases are known as enzymes which tolerate large structural variations of the substrates and additionally are cheap and robust biocatalysts. The objective of this research was to perform a controlled biocatalytic degradation of the amide bonds in $N$-hydroxymethylacrylamide durable press finished cotton fabric in order to rest ore partially the strength loss, without deteriorating the creaseresistance effect.

\section{Experimental Part}

\section{Textile Materials and Durable Press Finish}

The fabric used in this study was desized, scoured and bleached cotton. The aqueous pad bath was prepared from $13 \% \mathrm{~N}$-hydroxymethylacrylamide (Aldrich) and $1.56 \%$ zinc nitrate hexahydrate (Aldrich) as catalyst. The cotton fabric was impregnated on foulard with $80 \%$ wet pick-up. The impregnated fabric was dried at $105^{\circ} \mathrm{C}$ for two minutes and then cured in a Verner Mathis curing machine at $175^{\circ} \mathrm{C}$ for $1.5 \mathrm{~min}$. Afterward the treated textile material was washed thoroughly in order to remove the remaining unreacted reagent and catalysts.

\section{Enzyme Treatment}

Commercial serine protease (EC 3.4.21.62) from bacillus microorganism, Alcalase ${ }^{\mathbb{R}} 3.0 \mathrm{~T}$ (Novo Nordisk), $3 \mathrm{AU} \cdot \mathrm{g}^{-1}$ solid, was applied in different concentrations and time at $\mathrm{pH} 7.5$ (0.1 M phosphate buffer) and $50{ }^{\circ} \mathrm{C}$, as indicated by the producer. $^{[10]}$

\section{Wrinkle Recovery Angle, Tensile Strength, Dyeability and FT-IR Analysis of the Fabrics}

Wrinkle recovery angle (WRA) and tensile strength of the $\mathrm{N}$-hydroxymethylacrylamide treated fabrics were measured according to AATCC test method 66-1990 and ASTM method D5035-90, respectively. Diffuse reflectance spectra of some samples were collected by Bomem MB-series FT-IR spectrometer, performing 100 scans for each spectrum. No smoothing function and baseline correction were applied. Potassium bromide was used to obtain the background spectrum. The effectiveness of the protease hydrolysis was assessed following the decrease of the amide carbonyl band intensity at $1667 \mathrm{~cm}^{-1}$. $^{[11]}$ The protease treated samples $(1 \mathrm{~g}$ each) were dyed with C.I. Acid Blue 25 (Aldrich) in concentration 5\% o.w.f. (of weight of fabric), at $60^{\circ} \mathrm{C}, \mathrm{pH} 3.5-4$, for $1 \mathrm{~h}$, in bath to fabric ratio of $20: 1$. The colour of the dyed fabrics was evaluated in terms of K/S values, calculated from the visible reflectance spectra measured by Datacolor system (LAV/Spec. Incl., d/8, $\left.\mathrm{D}_{65}\right)$.

\section{Results and Discussion}

\section{Duration of the Enzymatic Hydrolysis}

The time-dependent effect of the protease product $\left(0.5 \mathrm{~g} \cdot \mathrm{1}^{-1}\right)$ on the properties of durable press finished fabric is represented by the results in Figure 1. The strength loss recovery of the crosslinked fabrics, due to the protease treatment, reached about $15 \%$ after 30 min of enzyme reaction. Thus nearly one half of the strength loss caused by the crosslinking was recovered during the enzymatic hydrolysis. Prolonging the reaction time did not provide further strength improvement. The enzymatic process provoked WRA decrease of up to $8 \%$. These changes in the mechanical characteristics of the fabrics occurred during the first 30 min of reaction.

The short time, sufficient to improve the tensile strength of the fabrics, renders the enzymatic process suitable for continuous operations in textile practice.

Comparative alkaline hydrolysis of the crosslinked cotton, carried out with $0.1 \mathrm{M} \mathrm{NaOH}$, at $50{ }^{\circ} \mathrm{C}$ for $30 \mathrm{~min}$ did not provide better recovery of the mechanical strength (about $10 \%$ ), however caused twice higher loss of the durable press effect (about 15\%) compared to the enzymatic process (Table 1).

The cleavage of the amide bonds in the cross-linked cotton is expected to produce carboxylic and amine end

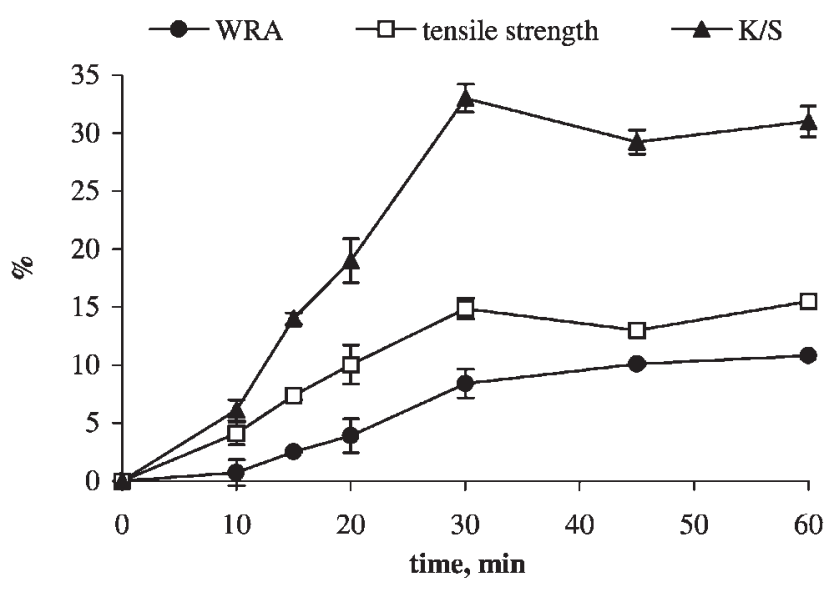

Figure 1. Time dependence of tensile strength recovery, WRA decrease and acid dye dyeability of durable press finished cotton (13\% $N$-hydroxymethylacrylamide/1.5\% $\left.\quad \mathrm{Zn}\left(\mathrm{NO}_{3}\right)_{2} \cdot 6 \mathrm{H}_{2} \mathrm{O}\right)$, hydrolyzed by $0.5 \mathrm{~g} \cdot 1^{-1}$ protease. 
Table 1. Tensile strength and WRA of cotton fabric treated with $13 \% \mathrm{~N}$-hydroxymethylacrylamide/1.5\% $\mathrm{Zn}\left(\mathrm{NO}_{3}\right)_{2} \cdot 6 \mathrm{H}_{2} \mathrm{O}$ and hydrolyzed by $\mathrm{NaOH}$ or protease for $30 \mathrm{~min}$.

\begin{tabular}{lcc} 
Fabric & Wrinkle recovery angle, $(\mathrm{w}+\mathrm{f})$ & Strength \\
\cline { 2 - 3 } & degree & $\mathrm{N}$ \\
\hline Blank & 129 & 590 \\
Durable pressed & 291 & 405 \\
Durable pressed and enzymatically treated & 266 & 465 \\
Durable pressed and alkaline treated & 242 & 445
\end{tabular}

groups. Thus the dyeability with an acid dye (C.I. Acid Blue 25) could be considered as an indirect indication for the occurrence of the hydrolysis reaction. The K/S values (e.g. dyeability) of enzymatically treated fabric notably increased (by 30\%) compared to the K/S values for the nonhydrolyzed one (Figure 1). Thus we may interpret the increased affinity of the protease-hydrolyzed fabric towards an acid dye as due to the appearance of free amine groups, coming from the amide bond breaking. After $30 \mathrm{~min}$ the dyeability of the enzymatically treated fabrics reached saturation.

The intensity of the amide carbonyl peak at $1667 \mathrm{~cm}^{-1}$ decreased with the increase of the hydrolysis time. Most significant decrease of the signal was observed for reaction times up to $20 \mathrm{~min}$. The carbonyl band intensity reached a plateau after $30 \mathrm{~min}$ of enzymatic treatment, e.g. no further hydrolysis occurred.

When considering enzymes that could hydrolyze peptides it should be noticed that the amide bond is very stable (e.g. in contrast to esters, particularly when exposed to water), presenting a planar, resistant to deformation structure. The serine proteases hydrolyze amides and esters, the latter much easier since they are less subject to resonance stabilization. The amide hydrolysis proceeds through two steps, acylation and deacylation, where the formation of acyl-enzyme intermediate is the rate-limiting step (Scheme 2). A property, shared by all serine proteases is the hydrogen-bonded triad of Asp-His-Ser. The enzyme is acetylated on the Ser residue. An important feature in the catalytic reaction is the formation of an ester between the hydroxy group of serine and the "acyl" portion of the substrate, with release of the "amino" portion of the substrate as the first product, $\mathrm{P}_{1}$. For the release of the second product $\mathrm{P}_{2}$ a reaction with water is necessary. Since more than one amide group in the durable press finished cotton fabric might react with the enzyme, many end amino and carboxylic groups may appear. When a nucleophile, such as amine, is present in the reaction between protease and substrate, a transacylation reaction with the amine might occur and the rate of the disappearance of the substrate becomes steady, e.g. further hydrolysis would be inhibited. The amide bonds in the cellulose fibers crosslinked with $\mathrm{N}$-hydroxymethylacrylamide are not a typical substrate for the enzyme. In contrast to low molecular substrates, the products of the enzyme hydrolysis remain on the fabric since the crosslinking agent is still bound to the cellulose via stable ester bonds, which are not susceptible to hydrolysis. Perusal of the data presented in the above Figure 1 and 2 and Table 1 supports the hypothesis that with the proceeding of the enzyme hydrolysis of the crosslinked amide product, the

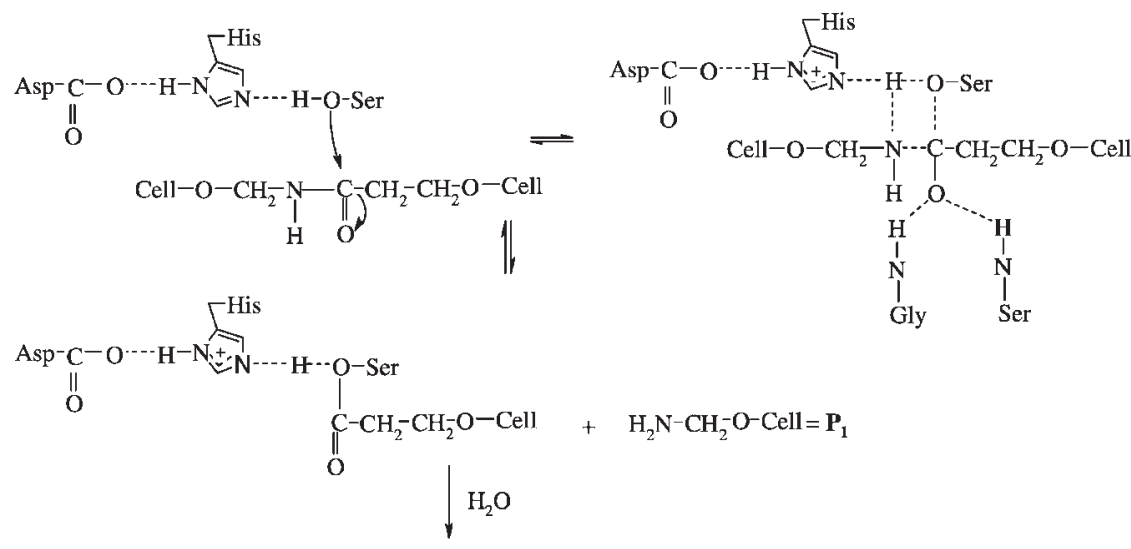

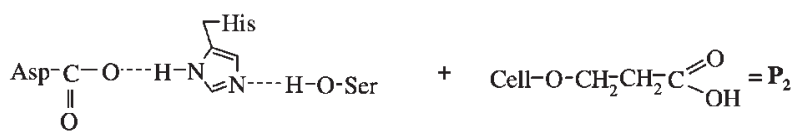

Scheme 2. Protease hydrolysis of amide cross-linked cotton. 


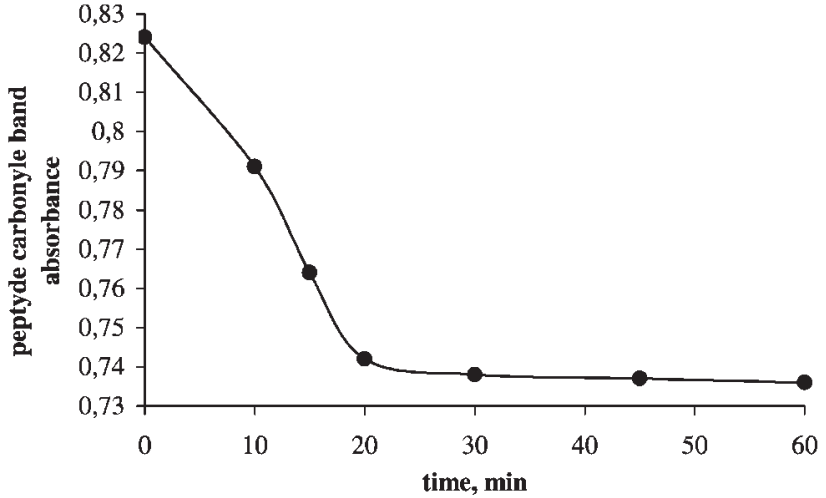

Figure 2. Time dependence of amide carbonyl band absorbance at $1667 \mathrm{~cm}^{-1}$ for cotton, cross-linked with $13 \% \mathrm{~N}$-hydroxymethylacrylamide $/ 1.5 \% \mathrm{Zn}\left(\mathrm{NO}_{3}\right)_{2} \cdot 6 \mathrm{H}_{2} \mathrm{O}$ and then hydrolyzed by $0.5 \mathrm{~g} \cdot 1^{-1}$ protease.

number of the nucleophilic amine groups should increase and thus the transacylation reaction would become predominant. Saturation was observed in the tensile strength recovery and in the dyeability of the fabrics. Another explanation for the saturation of the enzymatic effect might be the limited accessibility of the crosslinks to the large enzyme molecules. The WRA did not change proportionally to the improvement in strength, due to the fact that the linker still remained on the fibers.

\section{Enzyme Concentration}

The effect of the enzyme concentration on the strength loss recovery and WRA was studied for $30 \mathrm{~min}$ of reaction. As it can be seen in Figure 3 the tensile strength recovery normally increases with the increase of the concentration. At $0.5 \mathrm{~g} \cdot 1^{-1}$ protease, the strength recovery reached approximately $15 \%$. Above this concentration the amount of the enzyme did not cause any further improvement of fabric tensile behavior. The decrease of the WRA was up to $9 \%$ and followed the same concentration dependence. The dyeability of the fabrics with an acid dye increased rapidly

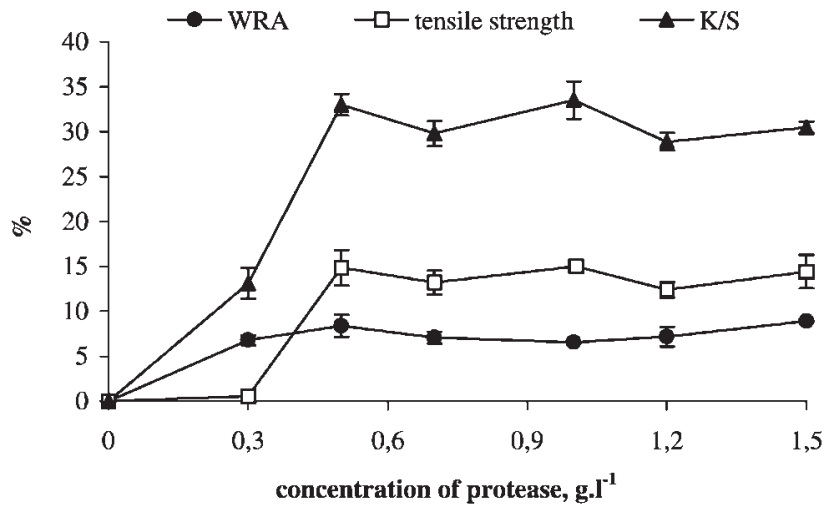

Figure 3. Effect of protease concentration on the tensile strength recovery, WRA and acid dye dyeability at $30 \mathrm{~min}$ reaction time.

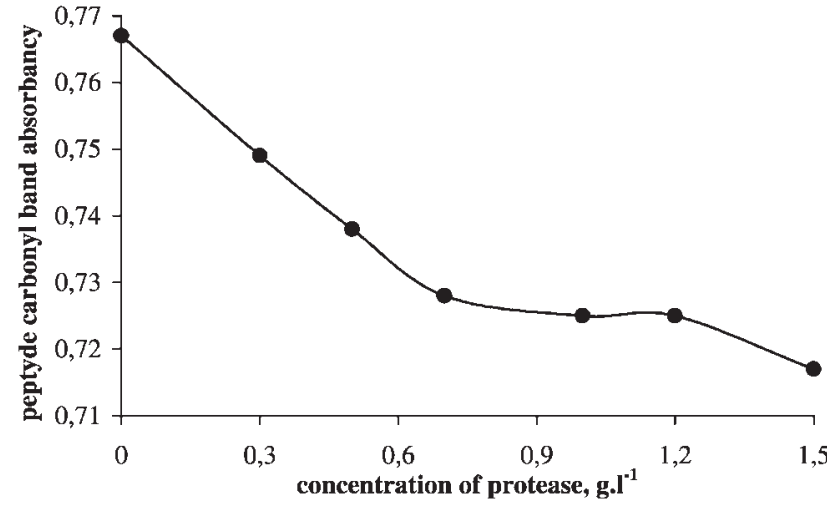

Figure 4. Amide carbonyl band absorbance at $1667 \mathrm{~cm}^{-1}$ of cotton cross-linked with $13 \% \mathrm{~N}$-hydroxymethylacrylamide/1.5\% $\mathrm{Zn}\left(\mathrm{NO}_{3}\right)_{2} \cdot 6 \mathrm{H}_{2} \mathrm{O}$ and then hydrolyzed by different concentration of protease for $30 \mathrm{~min}$.

for protease concentrations up to $0.5 \mathrm{~g} \cdot \mathrm{1}^{-1}$ and then remained steady independently on the amount of enzyme. The inhibition of the enzyme hydrolysis is reflected as well in the decrease of the intensity of the amide carbonyl peak at $1667 \mathrm{~cm}^{-1}$ in the infrared spectrum of the fabrics (Figure 4).

\section{Conclusions}

In this research protease enzymes were used to recover the tensile strength loss of $\mathrm{N}$-hydroxymethylacrylamide crosslinked cotton fabrics. Since the ether bonds formed between the product and the cellulose are not susceptible to enzymatic hydrolysis, we selected an alkaline serine protease able to attack the amide bond in the linker itself. The enzymatic hydrolysis of the amide bond in the cross-linked cellulose resulted in about 15\% strength loss recovery coupled with up to $8 \%$ decrease of the crease-resistance effect. The occurrence of protease hydrolysis of the amide finish was additionally confirmed by the decrease of the intensity of the amide carbonyl peak in enzymatically treated cotton samples and their improved dyeability with an acid dye. A short time, low concentration enzymatic process, performed at mild to the textile material conditions - neutral $\mathrm{pH}$ and low temperature - could be efficient to partially restore the tensile strength of amide crosslinked cotton fabrics, slightly damaging their crease-resistance. In contrast, in the conventional alkaline hydrolysis the deterioration of the wrinkle-resistance of the fabrics predominates on the recovery of the strength loss.

Acknowledgement: We would like to thank the HPMF-CT2000-00868 project for providing the grant to Dr. Tzanov.

Received: June 11, 2002

Revised: July 9, 2002

Accepted: July 11, 2002 
[1] J. Frick, R. Harper, Text. Res. Inst. 1982, 2, 141.

[2] R. H. Manly, "Durable Press Treatment of Fabrics", Park Ridge, New Jersey 1976, p. 104.

[3] US 3561916 (1971), inv.: W. F. Britinger.

[4] U. Meyer, K. Mueller, H. Zollinger, Text. Res. J. 1976, 46, 813.

[5] A. L. Murphy, M. F. Margavio, C. M. Welch, Text. Res. J. 1971, 41, 22.

[6] S. H. Zeronian, N. R. Bertoniere, K. W. Alger, K. W. Duffin, M. S. Kim, L. K. Dubuque, M. J. Collins, C. Xie, Text. Res. J. 1989, 59, 484.
[7] In-Sook Kang, C. Q. Yang, W. Wei, G. Lickfield, Text. Res. J. 1998, 68, 865 .

[8] T. Tzanov, A. Cavaco-Paulo, M. Stamenova, R. Betcheva, Macromol. Rapid Commun., in press.

[9] A. Cavaco-Paulo, ACS Symp. Ser. 1998, 687, 36.

[10] “Alcalase ${ }^{\circledR}$ manual instruction", Enzyme Business, B259fGB Nov. 1998, Novo Nordisk A/S.

[11] R. M. Silverstein, G. C. Bassler, T. C. Morril, "Spectrometric Identification of Organic Compounds", $5^{\text {th }}$ edition, John Wiley \& Sons, Toronto 1991, p. 102-130. 